\title{
Research on Influencing Factors of Welfare Level about Left-behind Children in China Rural Areas
}

\author{
Anjun $\mathrm{Hu}$ \\ College of Economics and Management, Sichuan Agricultural University \\ No.36, Xing Kang Road, Yaan 625014, Sichuan, China \\ Tel: 86-131-5854-3643E-mail: haj916@yahoo.cn \\ Dongmei Li (Corresponding author) \\ College of Economics and Management, Sichuan Agricultural University \\ No.36, Xing Kang Road, Yaan 625014, Sichuan, China \\ Tel: 86-138-8160-4197Ｅ-mail: cndldm@163.com \\ Mingming Liu \\ College of Economics and Management, Sichuan Agricultural University \\ No.36, Xing Kang Road, Yaan 625014, Sichuan, China \\ Tel: 86-150-0831-1205Ｅ-mail: hnlm.1986@163.com
}

Received: October 22, 2010 Accepted: November 5, 2010 doi:10.5539/jas.v3n2p223

\begin{abstract}
Based on the survey data of 360 left-behind children at junior school in Xinyang city Henan province in China, the welfare of left-behind children was analyzed by using Amartya.Sen ability method theory and fuzzy mathematics. The results showed that left-behind children's material welfare of the economy increased, but their social mental welfare level declined when their parents went to work at other cities. As a result, the level of total welfare utility is low. At last, in order to increase the general welfare of left-behind children, policies and suggestions were provided according to the analysis.
\end{abstract}

Keywords: The rural migrant workers, Left-behind children, Welfare

\section{Introduction}

In recent years,more and more workers are needed in the city construction because of the rapid economy development in China. Meanwhile, some farmers also gradually expect higher incomes, and a large number of rural surplus labors shift to work at the other city. Most of them with young children in their families are in their prime and full of vigour. Due to income, policy constraints and other reasons, it is difficult for the minor children of those migrant workers to relocate with their parents,most of them are looked after by their relatives, the friends of their parents, neighbors or live independently, and large-scale left-behind children are formed.

The survey and analysis report of family education about rural left-behind children,from China federation of women on May 25, 2009, said the number of China rural left-behind children topped 58 million because large numbers of parents went out for working at other cities. Large numbers of left-behind children affect millions of families, also influence rural families to improve the level of comprehensive benefits. In this paper, therefore, investigating the each influencing factor about welfare indicators of left-behind children and analyzing total welfare level can contribute to have an grasp of the overall situation of left-behind children in Chinese rural, it is usefull for designing fit policies and measures to improve welfare of left-behind children, promote dearness peace of family in rural and harmonious order of sociality. They are of great practical significance.

Under current circumstance of social transition in China, the surplus rural labors are transferring to city. Left-behind children, as a new social problem in China, is attracting wide attention, and have been researched substantially by many scholars. Juhua Yang, Chengrong Duan (2008) and Ni Wu ( 2004) considered that these 
young migrant workers would like to continue to increase revenue, and thus choose to go out for work or business, however, it was difficult to resolve their children receiving education in a city. So their children had to stay at home in the rural, or were taken care by the other family members, relations and friends, resulting in a large number of children left behind. Xiuying $\mathrm{Li}$ and $\mathrm{Ni} \mathrm{Wu}$ (2004) considered that most of left-behind children lacked of motivation of learning, the study goal was not explicit, the study habits were poor, and the learning record was backward because of lacking supervision or involving in children's learning too little from the temporary guardian. Qingfeng Li (2002) thought that the communication and contact frequency between migrant parents and left behind children were declined, and the way of communication was a single mode and limited, which made the family groups impact on the function of children's education greatly weakened, and caused children lacking of family socialization in the compulsory education. Xiuying Li and Lijing Li (2004) held that the left-behind children lacked of opportunities to communicate with their parents at home, when they encountered problems, they mostly solved in their own ways. Due to the lack of proper parental guidance, they were more prone to serious psychological problems. Hong Lin (2003) analyzed that the left-behind children was in the period of adolescent emotional changes, and separated from parents for a long time,and the needs of their physical and psychological were not met. As a result, negative emotions had been plaguing them, and cause them self-esteem, pessimistic, withdrawn. Most children missed their parents, they wanted to meet regularly with their parents or be together with their parents. From the studies above, we can get that most scholars make related research from reliving, education, learning, daily behavior, the perspective of communication and psychology studies of children left behind, but the studies on the welfare point of view are few. In this condition, this paper will give the empirical study from welfare point of view on children left behind.

\section{The analysis about welfare theory, the selection of variables, hypothesis and data}

\subsection{Theoretical analysis of the welfare}

\subsubsection{The overviw of the theory}

To analyze and measure the benefits, at first, we should make clear what welfare is, the founder of welfare economics. Pigou (A.C.Pigou) considered that a person's welfare lay in his own satisfaction, which can be satisfied because of the possession of goods, and also could be other reasons (such as knowledge, feelings, and desires, etc).Under his subject of the research, the benefits were confined to be related with the economic, directly or indirectly related with the amount of money, and this is called the welfare benefits of the economy. Later, part of economists thought that utility was the index or tools of measuring welfare. But the utility of people is kind of subjective psychological evaluation, so this kind of welfare theories could be called subjectivism welfare theories. Meanwhile,other economists defined and measured benefits from an objective perspective, such as income, wealth, commodities, consumer spending, the basic goods and resources, and subjectivism welfare theories came forth.

\subsubsection{Theoretical analysis framework}

Based on the precious research, Amartya.sen clearly pointed out that the welfare of people should be examined with the features, capabilities and freedom, and then examined inequality, which is the ability approach theory.According to Sen's definition, function measured the level of benefits that had achieved, ability measured the potential or possible level of benefits. So-called function refers to a person's achievement that he or she can do something or be already in a state. The capability, as a conception derived from capacity, is the potential combination of various functions that a man could achieve and choose freely in a different way of life. Ability itself is not functional, but the ability is the functional ability of achievement, and is real freedom person to choose their thought lives.

Sen (1993) pointed out that the core of capabilities approach was that people could take action and achieved the status of value according to the individual's ability. In this viewpoint, life was seen as the set of interrelated functional activities, the assessment of the welfare could be achieved with evaluation of these components. The functional and practical ability are closely linked with the individual characteristics and social economic conditions. In fact, the set of ability can not be directly observed, generally using the empirical functional activities to analyze the benefit. Therefore, this paper will use Amartya - Sen's capability approach theoretical framework in the functional space to analyze the welfare of rural left behind children in China.

\subsection{Selection of variables and research hypothesis}

According to the theory analysis above, this paper respectively establish welfare function space of rural left-behind children with six aspects which include the guardian of left-behind children, the changes of material that left-behind children received, the left-behind children health, the situation of relationship between parents 
and children left behind, the education condition and the psychological state of left-behind children. In fact, the value of left-behind children can include many aspects, however, in order to grasp the main welfare function of left-behind children in rural,and combine with the present condition of children left behind and the situation of the rural areas in China, this paper select the factors above to establish hypothesis about the welfare of left behind children in rural.

2.2.1 The situation that the guardian looked after left-behind children. In the case of left-behind children's parents leaving out, the welfare of left-behind children is dependent upon the other guardians, left-behind children's education and quality of life lie on the quality of care from the guardian. Meanwhile, the left-behind children will have aloneness because their parents went out, then how to eliminate this aloneness also largely depends on the psychological care from the guardian. In real life, children are short of the ability of healthy living, we can imagine that some regulation is better than no one monitoring, so we have hypothesis that the supervision from the guardian has positive influence on the left-behind children welfare.

2.2.2 About the material conditions of left-behind children after parents going out. Although using the material to reflect the welfare state of left-behind children has some flaws, it is still an important way to achieve well-being, especially in the economical backward rural areas. The condition of material is an important factor reflecting the benefits, thereby we consicer the material situation of children left behind as the functional composition of welfare indicators. With the increase of income, migrant workers will give their children's much more material, this article assumes that material conditions of left-behind children have a positive impact after their parents going out for work.

2.2.3 The health. For the left-behind children in China rural, their living conditions are related to the economic income of their parents, left-behind children are in growth and development stage, the living conditions have effect on their health. Therefore, health status should be a measure of the functional level for child welfare indicators. As the increase of material and economic of the migrant workers, this article assumes that the health status of left-behind children will show good trend.

2.2.4 The situation of relationship between parents and left-behind children. French Dr.Christian Spitz advised parents nurturing your children and spending more time with them together, because the family's comfort and care were beneficial for children growing.For minor children whose parents left out, feelings of alienation between them are appear constantly, their inner emotional needs are often ignored by the parents and guardians, and there is little emotional exchange when they communicate. Of course, this can not satisfy the emotional needs of children left behind, the emotional needs is normal needs of human and an important part in the welfare space of the left behind children. Therefore, this article assumes that Parent-Child Relationship will diminish because parents went other cities for working,and make the welfare of children left behind decline.

2.2.5 Education and management. Left-behind children are in knowledge and imitative period, the parents are the best teacher for the child, words and deeds of their parents play an important role in the children's education. children need get timely guidance when the environment changed, and the level of their quality of life is also related to the education, so the education management should be incorporated into benefits for the left-behind children. While the parents went to other cities for working, the family education became weak. In this case, this paper assumes that education and management of left-behind children declined, and produce negative influence on the welfare level.

2.2.6 Psychological state. Zongkui Zhou (2005) thought that a considerable number of children had a sense of loss and discomfort when their parents went out. According to Youguang Huang (1991), the definition of individual welfare.these sad, lonely, happy, and other psychological conditions should constitute a factor in the welfare of children left behind.This article assumes that the psychological status of left behind children will have a negative impact on its welfare when their parents went other city for work.

\subsection{Data explanation}

\subsubsection{Research areas and data sources}

Xinyang city is located in south of henan province in China, as a "China Livable City", its total area is 18,900 square kilometers, the number of population is 8 millions. Since 1990's, in order to improve the economic income, most youths become migrant workers working at southeast coastal developed areas. Though their family income has greatly increased, their children joined the ranks of left-behind children who are widespread in China, how about the level of welfare of left behind children. In this context, the factors infulencing welfare level of children left behind will be focused.

We selected two counties (one is Gushi County, the most populous county in the central plains, the vast majority 
of rural young are migrant workers, forming a large number of children left behind; the other is Huangchuan County, as an important transport hub, transport facilities open the way for population flow) in Xinyang City as the survey area in December 2009, we randomly selected students at junior school to complete the questionnaire, a total of 360 questionnaires, 255 valid questionnaires were received.

Among those surveyed,more than $85 \%$ of their parents are migrant workers,the average age was 14 years old. The proportion of girls is $60 \%$ in all the left- behind children, the reason is that most of them will choose boys, if the migrant workers in rural areas have opportunity to take care of their children closely at hand.This also clearly showed that the preference for sons in rural areas still exists. In the survey, $68.24 \%$ of the left-behind children are brought up by their grandparents, however, these guardians are older and less educated, so that they are unlikely to be provided such as the support and help for learning, spiritual encouragement and counseling and psychological comfort and adjustment, which are the important benefits functions for the left-behind children. Main duties for these guardians may be to make sure the left-behind children clothed and fed, but this is only one aspect of many welfare functions for the left-behind children. (table 1)

\subsubsection{Data processing instructions}

Chinese scholars Youguang Huang (1991) indicated that a personal well being could be looked as personal benefits, whether happiness can be attributed to physical pleasure and pain, or mental pleasure and pain. YuePing Sun (2004) considerred that a variety of benefits were physical or psychological well being or happiness while desires or needs were met, involving people's material needs and spiritual needs. Combined with A.C.Pigou elaborated on the benefits in the preceding mention, we can define the material status, the guardianship status, and the health care status as the economic material welfare,and the reason is that these aspects are derived from the economic substance which are received from the parents who went to work at other cities. For the family status, education management status and psychological status, we can define them as the social spiritual welfare from the point that they are linked with the spirit civilization of the left-behind children.

For data processing, on one hand, as it involves the welfare evaluation, while in the questionnaire process, those left-behind children can not give a accurate answer when investigated, but only gave qualitative description and subjective evaluation, which are much more qualitative variables. On the other hand, in order to make the measure comparable, the analysis of observational data is described in table 2 , the original code has been re-assigned by the difference of option at the same scale.

\section{Methodology and the analysis of results}

\subsection{The selection of Model}

Sen (2002) defined the welfare as "a persona chooses the liberty of essence in life which has reason to cherish". $\mathrm{He}(1992)$ also thought welfare as a wide and the fuzzy concept in the certain extent. We cannot accurately define it because of this fuzziness. On the other hand, the selection of some evaluation indexes belongs to the subjective judgment factors which also have certain fuzziness, therefore, we choose the fuzzy mathematics as analysis method in paper.

3.1.1 The description of fuzzy set. The universe $U=\left\{x_{1}, x_{2}, \ldots \ldots, x_{n}\right\}$ represents the welfare set of the left-behind children, let the set A indicates the welfare of left behind children in investigated, then A can be expressed as $\tilde{\mathrm{A}}=$ $\left\{\left(\mathrm{x}_{1}, \mu_{\mathrm{A}}\left(\mathrm{x}_{1}\right)\right),\left(\mathrm{x}_{2}, \mu_{\mathrm{A}}\left(\mathrm{x}_{2}\right)\right), \ldots,\left(\mathrm{x}_{\mathrm{n}}, \mu_{\mathrm{A}}\left(\mathrm{x}_{\mathrm{n}}\right)\right)\right\}$, where $\mathrm{x} \in \mathrm{U}, \mu_{\mathrm{A}}$ indicates the membership of $\mathrm{x} \in \mathrm{A} . \mu_{\mathrm{A}}(\mathrm{x}) \in[0,1]$. In the fuzzy mathematics, the larger membershipgrade is, the greater the likelihood of $\mathrm{x} \in \mathrm{A}$ is. On the contrary,the smaller membershipgrade is, then the less the likelihood of $x \in A$ is.

3.1.2 The selection of membership function. The key problem of using the fuzzy mathematics is how to choose the appropriate membership functions. The choice of membership functions depends on the background of study and type of function index. Miceli (1998) thought that the indicator variables were divided into 3 types, virtual binary variables, continuous variables and virtual qualitative variables. Let $\mathrm{x}_{\mathrm{i}}$ be the $\mathrm{i}$-th functional subset of the left-behind children welfare determined by the primary indicators $\mathrm{x}_{\mathrm{ij}}$, and $\mathrm{x}=\left[\mathrm{x}_{11} \ldots \mathrm{x}_{\mathrm{ij}}, \cdots\right]$.

During the process of evaluating the left-behind children welfare, we can not get quantitative data, but only received qualitative description, and most of which is the virtual qualitative variable. Virtual qualitative variable is subjective evaluation for research objects in different degree. For example, we can set 4 states about satisfaction evaluation as below, greatly satisfied, generally satisfied, dissatisfied, less dissatisfied. Assume there are $\mathrm{m}$ states in the study, then assign value $\mathrm{x}_{\mathrm{ij}}=\left\{\mathrm{x}_{\mathrm{ij}}^{(1)}, \cdots, \mathrm{x}_{\mathrm{ij}}{ }^{(\mathrm{m})}\right\}$ for this $\mathrm{m}$ states, which are equidistant distribution. The greater of the value is, the better of the welfare is, usually we set: $\mathrm{x}_{\mathrm{ij}}{ }^{(1)}<\cdots<\mathrm{x}_{\mathrm{ij}}{ }^{(\mathrm{k}) \ldots}<\mathrm{x}_{\mathrm{ij}}{ }^{(\mathrm{m})}$, and $\mathrm{x}_{\mathrm{ij}}^{(\mathrm{k})}=\mathrm{k}(\mathrm{k}=1, \cdots, \mathrm{m})($ Miceli, 1998).

Cerioli and Zani (1990) designed this qualitative variable of virtual function as below: 


$$
\mu\left(x_{i j}\right)=\left\{\begin{array}{cc}
0 & x_{i j} \leq x_{i j}^{\min } \\
x_{i j}-x_{i j}{ }^{\min } & x_{i j}^{\min }<x_{i j}<x_{i j}^{\max } \\
x_{i j}{ }^{\max }-x_{i j}{ }^{\min } & x_{i j} \geq x_{i j}^{\max } \\
1 &
\end{array}\right.
$$

Where $x_{i j}^{\max }$ and $x_{i j}^{\min }$ respectively indicate maximum and minimum values of indicators $x_{i j}$. When get the primary index membership, we need add membership to a comprehensive index, this involves weight problems of function pointer, which is the key point of final fuzzy evaluation. Cheli and Lemmi (1995) defined the weight structure as $\omega_{i j}=\ln \left[\frac{1}{\overline{\mu\left(x_{i j}\right)}}\right]$, and $\overline{\mu\left(x_{i j}\right)}=\frac{1}{n} \sum_{p=1}^{n} \mu\left(x_{i j}\right)$ indicate the mean value of the $\mathrm{j}$-th index in the $\mathrm{i}$-th functional subset index of $\mathrm{n}$ left-behind children. On the basis of accessing the weight and membership of primary targets, we can calculate the degree of membership of each function.

Cerioli and Zani (1990) proposed using the formula $f\left(x_{i}\right)=\sum_{j=1}^{k} \bar{\mu}_{i j} * \omega_{i j} / \sum_{j=i}^{k} \omega_{i j}$ to calculate the degree of membership of each function. Where $\mathrm{k}$ represents that i function subset includes $\mathrm{k}$ primary indicators. The formula can make the overall welfare level of left-behind children increase when improved the welfare index membership level of each left-behind children under the same conditions.

\subsection{Fuzzy evaluation and discussion of results}

After the fuzzy evaluation and calculation about the welfare state, the function of the membership and weight for the left-behind children in China rural, based on table 2, we can draw the following conclusions.

3.2.1 The care of guardian. The functional benefit index $\mathrm{X}_{1}$ which derived from the guardian is 0.759 in table 2,and at a good level. Generally speaking, after their parents are out, migrant parents often send part of remittances to guardian, which is part of the guardian income, so that the guardian can release part of the energy to take care of children left behind.

3.2.2 Material gain. The income of peasantry increases when they worked at city, they send left-behind children money or material to make left-behind children material wealth, which exists in reality, and consistent with the analysis of data in this paper (the membership of X2 is 0.642 in table 2, at a high level). This may be the major positive effect for the left-behind children after their parents going out of the countryside.

3.2.3 State of health. After the peasant migrant went other city for working, their family income significantly improved, thus the material life of left-behind children get enriched. During the investigation, we learned that parents were particularly interested in left-behind children health condition when they telephone. In the meantime, the most attention of guardians in daily life is left-behind children's health. Therefore, for the aspects of physical condition, the function index is 0.547 , the trend is good.

3.2.4 Affection. The value of index X4 is 0.457 , derived from the calculation results, which is at a low level. When parents worked outside, the emotional between the left-behind children and their parents has a distance, the parents and guardians often ignore their inner world and emotional needs. As a result, the left-behind children are starving for affection. Therefore, the family welfare function of welfare level is low.

3.2.5 Education management. The level of benefits of education management is only 0.466 shown in table 2 , which is in the low level. We understood that the most important task for for these guardians may be to make sure the left-behind children would never want for bread, but ignored the children's physical and mental health and education of personality from survey. On the other hand, for the parents who are far away from their hometown, the left-behind children's education and management are beyond their grasp, education management of left-behind children need effective supervision between family and school. In the absence of family education, education management of left-behind children from school is in an embarrassing position, and education management of left-behind children clearly weakens.

3.2.6 The psychological state. The value index X6 is only 0.370 in table 2, which means that the benefits level of left-behind children getting from the psychological function is very low. Due to left-behind children separating 
from their parents for a long term, parent-child relationship is not perfect, As a result,children were starving for affection, the unrest on mood and desolated feeling for the left-behind children are easy to appear, then they often appear psychological development problem.

3.2.7 The overall welfare level of left-behind children from the economic benefits and social spirit benefits is low (Total membership of fuzzy functions is 0.486 ), which is in poor condition. The economic condition of migrant farmers improved after they work out, which make the left-behind children's supplies get improved. With the increase of material, the guardian will also pay more attention to left-behind children, in such circumstances, the health of left-behind children will improve,So economy material welfare index is 0.636 , at a good level. However, the level of welfare function of left-behind children that originated from the family, education, management, psychology stay poor (Social moral well-being welfare level is only 0.425 in table 2). In the circumstances of negative effect than positive, the overall welfare of left-behind children will have negative effect, and the total welfare of left-behind children is poor.

\section{Conclusions and Suggestions}

From the calculation and analysis above, we can see that overall standard of children's welfare was low after their parents became the rural migrant workers working at city, the reason is that the social mental welfare of the children's social indicators are too low, thus the overall welfare indicators stay down, in order to improve the overall welfare of left behind children, whose social mental welfare should be improved. So how to enhance the welfare of left-behind children? This requires the state, society, families, schools and other groups to cooperate with each other, and take effective measures to create a good environment for the left-behind children to grow up healthily.

\subsection{Policy system and school education}

Firstly, reforming the household registration system, gradually weakening or even cancelling the registration and system, breaking the dualistic economic system that has been available for years in China. Secondly, reforming rural education system, the investment of rural education should be increase,and equip with psychological counseling tutor in China rural school, fully understand the mental health status of the left-behind children and give psychological counsel and help. Finally, actively encourage and support the city public schools to accept rural left-behind children whose parents work at city, and lower entrance requirements.

\subsection{Family}

In the children's growth process, parents and families play an irreplaceable important role. The parents should try to preserve complete family function, when they go out for work, parents try not to migrant work at same time. Try to increase frequency of going home, improve communication with children, give left-behind children the practical affective care and guidance of education, let left-behind children feel parental care and the warmth of family.

The problems of rural left-behind children in China must be faced in the social transition process of rural development, in order to comprehensive understand and solve the problem on left-behind children whose parents go out for work, research on children left behind can not only be limited to the investigation of certain areas and analysis of individual areas, but also do comprehensive study, so that the family environment, living environment and learning environment for left-behind children can get improvement, ensure the healthy growth for left-behind children, in order to improve the overall welfare left-behind children.

\section{References}

Arthur Cecil Pigou. (1932). The Economics of welfare. The Commercial Press, pp.11

Cerioli A, Zani. (1990). A Fuzzy Approach to the Measurement of Poverty”, in Dagum, C. and Zenga, M.(eds), Income and Wealth Distribution, Inequality and Poverty. Studies in Contemporary Economics, SpringerVerlag,Berlin, pp.272 284.

Cheli, Lemmi. (1995). A Totally Fuzzy and Relative Approach to the Multidimensional Analysis of Poverty. Economic Notes, Vol. 24, No. 1, 115 133.

Huang, Youguang. (1991). The Economics of welfare. Northeastern University Finance \& Economic press, pp:3

Li, Xiuying. (2004). Investigation and Reflection on Rural "students left". Journal of Chinese Women's Movement, 10, 35-37.

Li, Qingfeng. (2002). The effect of the movement of rural labour on the diveloping of "left-behind children". Journal of Shanghai Research on Education, 9, 25-28. 
Lili Jing. (2004). Social anxiety due to "Three girls running away". Journal of China Nationalities Education, 5, 16-19.

Lin Hong. (2003). Investigation of the Present Situation about Fujian Guarded Children Education.Journal of Fujian Normal University(Philosophy and Social Sciences Edtion), 3,132-135

Sen.Amartya, Wang Liwen, Yu Zhanjie (translation). (2006). On Economic inequality, inequality reexamined. Social Science Documentation Publishing House, pp.27 29.

Sen.Amartya, Wang Yu, Wang Wenyu(translation). (2006). On Ethics \& Economic. The Commercial Press, pp.42 45.

Sen. Amartya. (1992). Inequality Reexamined. Harvard University Press, pp.60 62.

SunYuePing, LiuJun, TanJun. (2004). Applied Welfare Economic. Economic Management Press House, pp.10

Wu Ni. (2004). A Survey Report on the Education of Hometown-Remaining Children in Rural Areas. Journal of Educational Research, 1, 15-18.

Yang Juhua, Duan Chengrong. (2008). A Comparative Analysis of Educational Opportunities for Migrant,Stay and Other Children in Rural China. Journal of Population Research, 1, 11-21.

Table 1. Basic Information and Statistics survey data

\begin{tabular}{|c|c|c|c|c|}
\hline category & Definition & Coding & $\begin{array}{l}\text { Samples or } \\
\text { frequency }\end{array}$ & Ratio or frequency \\
\hline \multirow{2}{*}{ Gender } & Boys & 1 & 102 & $40.00 \%$ \\
\hline & Girls & 2 & 153 & $60.00 \%$ \\
\hline \multirow{5}{*}{ Age } & 12 years old & 1 & 12 & $4.71 \%$ \\
\hline & 13 years old & 2 & 60 & $23.53 \%$ \\
\hline & 14 years old & 3 & 75 & $29.41 \%$ \\
\hline & 15 years old & 4 & 63 & $24.71 \%$ \\
\hline & 16 years old & 5 & 45 & $17.65 \%$ \\
\hline \multirow{5}{*}{ Guardian Type } & Father & 1 & 6 & $2.35 \%$ \\
\hline & Mother & 2 & 9 & $3.53 \%$ \\
\hline & Parents & 3 & 33 & $12.94 \%$ \\
\hline & Grandparents & 4 & 174 & $68.24 \%$ \\
\hline & Relatives & 5 & 33 & $12.94 \%$ \\
\hline \multirow{4}{*}{$\begin{array}{l}\text { Migrant status of } \\
\text { parents }\end{array}$} & Parents are not out & 1 & 33 & $12.94 \%$ \\
\hline & Parents are out & 2 & 174 & $68.24 \%$ \\
\hline & Out the father & 3 & 42 & $16.47 \%$ \\
\hline & Out the mother & 4 & 6 & $2.35 \%$ \\
\hline
\end{tabular}

Table 2. Fuzzy Assessment of condition for the left-behind children welfare

\begin{tabular}{|l|c|c|c|c|}
\hline \multicolumn{1}{|c|}{ Indices } & Source code & Deassign & Membership & Weights \\
\hline Economy material benefits & - & - & 0.636 & 0.391 \\
\hline 1. The care of guardian $\mathrm{X}_{1}$ & Perfect, Average, Poor & $3,2,1$ & 0.759 & 0.101 \\
\hline 2. Material gain $\mathrm{X}_{2}$ & Augment, Constant, Diminution & $3,2,1$ & 0.642 & 0.142 \\
\hline 3. State of health $\mathrm{X}_{3}$ & Meliorate, Constant, Poor & $3,2,1$ & 0.547 & 0.148 \\
\hline Social moral well-being & - & - & 0.425 & 0.609 \\
\hline 4. Affection $\mathrm{X}_{4}$ & - & - & 0.457 & 0.182 \\
Parent-child relationship $\mathrm{X}_{41}$ & Augment, Constant, Diminution & $3,2,1$ & 0.463 & 0.089 \\
Parent-child motional $\mathrm{X}_{42}$ & Perfect, Constant, Weaken & $3,2,1$ & 0.451 & 0.093 \\
\hline 5.Education management $\mathrm{X}_{5}$ & - & - & 0.466 & 0.179 \\
Management status $\mathrm{X}_{51}$ & Enhance, Constant, Weaken & $3,2,1$ & 0.493 & 0.086 \\
Academic record $\mathrm{X}_{52}$ & Improve, Constant, Decline & $3,2,1$ & 0.444 & 0.093 \\
\hline 6.Psychological state $\mathrm{X}_{6}$ & Well, Constant, Deteriorate & $3,2,1$ & 0.370 & 0.248 \\
\hline \multicolumn{1}{|c|}{ Total fuzzy index } & & - & 0.486 & - \\
\hline
\end{tabular}

